\title{
Combustion modelling for a diesel engine with multi-stage injection using a stochastic combustion model
}

\author{
$\operatorname{AUTHOR}(S)$ : \\ Liu, L.; Horibe, N.; Ishiyama, T.
}

\section{CITATION:}

Liu, L. .... [et al]. Combustion modelling for a diesel engine with multi-stage injection using a stochastic combustion model. Proceedings of the Institution of Mechanical Engineers, Part D: Journal of Automobile Engineering 2014, 228(5): 518-534

\section{ISSUE DATE:}

2014-03-26

URL:

http://hdl.handle.net/2433/187391

\section{RIGHT:}

(C) 2014 by Institution of Mechanical Engineers. Reprints and permissions:

sagepub.co.uk/journalsPermissions.nav; この論文は出版社版でありません。引用の際に は出版社版をご確認ご利用ください。; This is not the published version. Please cite only the published version. 


\title{
Combustion Modeling for a Diesel Engine with Multi-Stage Injection
}

\section{Using a Stochastic Combustion Model}

\author{
Long Liu ${ }^{1, *}$, Naoto Horibe ${ }^{1}$, Takuji Ishiyama ${ }^{1}$ \\ ${ }^{1}$ Graduate School of Energy Science, Kyoto University \\ *Corresponding author: Address: Yoshida-Honmachi, Sakyo-ku, Kyoto 606-8501, Japan \\ Tel: $+81-75-753-5269$ \\ Fax: +81-75-753-5269
}

Email: liulong210@gmail.com

\begin{abstract}
This study presents the development of a phenomenological combustion model to simulate the combustion processes in diesel engines with multi-stage fuel injection. A newly developed zero-dimensional spray propagation model and a model of spray-to-spray interaction were combined with a stochastic combustion model, which had been developed for diesel combustion calculation in the cases of single-stage injection. In this model, the combustion chamber is divided into an ambient air zone and several spray zones, where the spray formed by each injection is treated as a spray zone. Turbulent mixing, fuel evaporation, heat loss, and chemical reactions, are calculated in each spray zone respectively. A zero-dimensional spray propagation model including the spray evolution after the end of injection (EOI) and the model of interaction between the sprays from sequent injections are developed to describe the spray behavior for the case of multistage injection. Then the developed combustion model is validated against the experimental data from a single-cylinder DI diesel engine with pilot/main two-stage injection, in which the pilot injection conditions are varied with fixed main injection timing. Based on the analysis of heat release rate, entrainment rate, and
\end{abstract}


the microscopic information inside the spray, such as probability density function (PDF) of equivalence ratio, the effects of wall impingement and interaction between adjacent sprays on fuel-air mixing rate and entrainment rate are formulized and employed to reproduce the measured histories of heat release rate. Reduction of fuel-air mixing rate is considered when the spray flows into the squish region after the wall impingement, which is effective to capture the measured decrease of pilot spray's heat release with advancing pilot injection timing. The effects of wall impingement of the main spray and the interaction between adjacent sprays are modeled to reproduce the heat release rate during the initial and later part of the mixing-controlled combustion. After these improvements, heat release rates of the test engine when varying the pilot injection conditions have been successfully predicted.

Keyword: Diesel engines, Multi-stage injection, Stochastic combustion model, Spray model, Entrainment rate, Fuel-air mixing.

\section{INTRODUCTION}

In order to satisfy a growing demand for mitigation of environmental impact and improvement of thermal efficiency, various technologies have been employed in diesel engines, such as high pressure fuel injection, variable injection timings, multi-stage injection, exhaust gas recirculation, turbocharging with intercooling and variable turbine geometry, exhaust aftertreatment and so on. Among these technologies, the injection control has played a significant role, especially the multi-stage injection is an essential approach for the latest engines to reduce $\mathrm{NO}_{\mathrm{x}}$, soot emissions and combustion noise simultaneously [1-5]. However, to determine the optimal injection strategies, many injection parameters such as injection pressure, timing and quantity, should be selected properly corresponding to the engine operating conditions. It brings a heavy work and high cost on experiments, moreover it is difficult to obtain the appropriate injection strategies without 
understanding the change in combustion process when varying these parameters. Thus an accurate and computationally efficient combustion model is needed for these parameters study.

As an effective approach, phenomenological combustion models are often developed to calculate the combustion process that is mainly represented by heat release rate in diesel engines based on important physical and chemical phenomena within limited calculation time requirements for studying parameters, such as the models in [6-9]. The stochastic combustion model [10-13] is one of such models for conventional and PCCI diesel combustion, in which a stochastic turbulent mixing model is combined with a global chemical kinetic model. Particularly, it is not only able to output reasonable macroscopic information such as incylinder pressure, average temperature, and heat release rate, but also can describe the heterogeneity of fuelair mixture using microscopic information including probability density function (PDF) of equivalence ratio and temperature, which are useful for analysis of the effects of fuel-air mixing on combustion and prediction of NOx and soot emissions. However, this model only focused on the single injection situations. Therefore, the aim of this study is to extend the stochastic combustion model to simulate the combustion in diesel engines with multi-stage injection.

According to the studies from combustion numerical simulation, chemical kinetics, and optical diagnostics, the ignition and combustion process in diesel engines are determined by the fuel-air mixing and chemical reaction [14]. Especially the injection parameters directly determine the fuel spray behaviors that affect the mixture formation significantly; as a result, the combustion characteristics are varied. Thereby, in order to capture the major features of combustion under multi-stage injection conditions, each injection is customarily treated to form a spray region, and relevant calculations including spray propagation, fuel evaporation, turbulent mixing, ignition, and chemical reaction are performed for each spray [15-18]. The challenges compared with single injection calculation come from the complicated additional influences of the 
former spray on the later spray. For instance, heat release of the former spray affects the thermodynamic properties of the ambient air in the cylinder, and consequently the spray propagation of the later spray is modified. On the other hand, once the later spray penetrates into the former spray region, the mixture of the former spray is entrained into the later spray, which decreases the air entrainment rate of the later spray so as to suppress the fuel-air mixing in the later spray. Meanwhile, the mixture entrained from the former spray also modifies the temperature and chemical species distributions in the later spray, so that has an impact on the chemical kinetics of the later spray. These influences indicate that the combustion of the later spray is significantly dependent on the physical and chemical properties of the former spray. Considering the wide range of injection timings, which is as an example found in early to close pilot injections, the later injection starts after the end of the former injection. Thereby the evolution of the spray after the end of injection (EOI) has to be taken into account to imitate these influences realistically. The spray behaviors after EOI are indicated quite different from that during injection by the fundamental studies on turbulent gas and diesel jets [19-23]. However, there is no zero-dimensional spray model to describe the spray development and air entrainment after EOI, and the spray-to-spray interaction models employed by a few researchers [16-18] require improvement for more precise prediction of combustion processes.

Currently, frequently used models of spray propagation are Wakuri's model [24], Siebers's model [25], and Hiroyasu's model [26], which only satisfy the spray propagation during injection with steady state and do not involve any information for that after EOI. In addition, the interaction between sprays from the sequent injections is another important respect when the later spray enters into the former spray region. It is usually treated as the entrainment from the former spray zone to the later spray zone [16-18], and the discrepancy exists on the amount of gas entrained in the later spray zone from the former spray zone. In reference [16], the entrainment of the later spray includes surrounding air and the gas from the former spray zone, and the gas 
amount from the former spray zone is determined by the volume ratio between the surrounding air and the former spray. Similar method can be found in [18], both of the burned gas and unburned gas are treated to entrain into the later spray zone, and burned mass fraction is the factor on the entrained amount of burned gas. In addition, the later spray is assumed to be injected into the former spray region [17], so that the entrained gas of the later spray only comes from the former spray zone. It should be noted that all of these interaction treatments assume that later spray entrains the gas from the former spray zone immediately when the later injection starts.

In this study, in order to further develop the stochastic combustion model for simulating the diesel combustion processes with multi-stage injection, a zero-dimensional spray propagation model including the spray evolution after EOI and model of interaction between the sprays from sequent injections have been developed. The calculation results were compared with experimental data from a single-cylinder test engine for pilot/main two-stage injection, and analysis was performed based on the heat release rates, entrainment rates, and PDFs of equivalence ratio to find out the reasons for the discrepancies of heat release rate between the simulation and experiment. Then the phenomena of the reduction of fuel-air mixing rate by sprays which flows into the squish region, enhancement of main spray entrainment rate by wall impingement, and suppression of entrainment rate by interaction between adjacent sprays were modeled and applied to improve the predictions of pilot spray's heat release rate, heat release rate after main injection during initial period, and heat release rate during late combustion period respectively. Finally, good agreement of heat release rates with experiment when varying the pilot injection timing and quantity has been achieved using the developed combustion model.

\section{MODEL DESCRIPTION}




\subsection{STOCHASTIC COMBUSTION MODEL}

The prototype of stochastic combustion model was a stochastic mixing model which was firstly proposed in [10] for conventional combustion in diesel engines. And then this model was modified in [11, 12, 13] to analyze the PCCI combustion process. This model employs a stochastic turbulent mixing process combined with a quasi-global chemical kinetics model to describe the non-homogenous combustion process in diesel sprays.

These models treat the fuel-air mixing process in diesel combustion as a stochastic process in which the fluid elements in a combustion chamber meet and exchange their properties each other to approach the homogeneous state. The heterogeneity of fuel concentration and temperature is described using the PDF $f(z$, $t)$, where $z=\left(h, y_{1}, y_{2}, \ldots, y_{\mathrm{n}}\right), h$ denotes the specific enthalpy and $y_{1}, y_{2}, \ldots, y_{\mathrm{n}}$ the mass fraction of chemical species. Evolution of the mixing and combustion is represented by the temporal change of $f$ due to the mixing, fuel injection, fuel evaporation, air entrainment into a spray, heat loss to the combustion chamber walls and chemical reactions. The change in $f$ due to turbulent mixing is simulated by modified Curl's collision and dispersion model [27], in which a randomly selected pair of fluid elements (stochastic particles) with an equal mass collides and coalesces, and then disperses with their $h$ and $y_{\mathrm{i}}$ values. The frequency of collision is determined by spray's turbulent kinetic energy which is mainly dependent on the injection conditions [10]. The air entrainment rate is determined using Wakuri's momentum theory [24] and the progress of fuel oxidation reactions is calculated by Schreiber's model [28] in each fluid element. In addition, the heat loss from wall is also considered using Woschni's equation [29]. For further details, please see the previous paper [10-12].

To apply this concept to spray combustion, the space in a combustion chamber is divided into a spray zone and an ambient air zone, and the injected fuel and ambient air are treated as a large number of fluid 
elements with same mass. The temperatures and chemical compositions of these elements provide the temporal variation of PDF for fluid thermodynamic states in the cylinder, and histories of in-cylinder pressure and average temperature can be calculated by the statistics of all the elements.

Thus, in the stochastic combustion model, fuel-air mixing and chemical reactions are simultaneously calculated. Therefore, the premixed and mixing-controlled combustion modes are realized depending on the balance between the mixing and chemical rates. When the fuel-air mixing rate is faster than the chemical reaction rate, the premixed combustion is dominant. On the contrary, the combustion is mixing-controlled when the chemical reaction rate is relatively higher than the mixing rate.

\subsection{MODEL'S CONCEPT}

In the above mentioned previous models, only one spray zone was considered to simulate the combustion with single-stage injection. In the present model, as shown in Fig.1, to simulate the combustion processes with two-stage injection, the volume in the cylinder is divided into three zones, including a first spray zone, a second spray zone and an ambient air zone. Fuel evaporation, turbulent mixing, chemical reactions, and heat loss are calculated in each spray zone in the same manner as in the previous models, meanwhile the entrainment mechanism is applied to describe the mass and heat transfer among these three zones. Based on the spray behavior, the specific process is considered as following. Before injection, air and EGR gas in the cylinder is treated as an ambient air zone that is composed of a large number of fluid elements. Then after the start of the first injection, the fuel is injected into the cylinder as fluid elements to form a first spray zone with entrained fluid elements from ambient air zone. After the end of the first injection, very lean mixture is formed near the injector tip due to the termination of fuel supply and the increase in entrainment rate after EOI, thereby the first spray tail is assumed to depart from the nozzle exit to the downstream. After the second injection starts, the first and second spray zones exist in the cylinder and the fluid elements of the 
ambient air zone are entrained into these two spray zones. Once the second spray tip overtakes the first spray tail, both of the fluid elements from the ambient air zone and the first spray zone are entrained into the second spray zone. If all of the fluid elements of the first spray zone were entrained into the second spray zone, these two spray zones were combined into one spray zone. To carry out this model's concept, two primary respects should be considered on the spray modeling. The one is the spray penetration including tip and tail, the air entrainment rate, especially for the case after the end of injection, and the other one is the interaction between the first and second sprays, which is represented by the entrainment from the first spray to the second spray.

\subsection{SPRAY PROPAGATION}

In most of the phenomenological combustion models, the diesel spray propagation is usually described based on momentum theory such as Wakuri's equations [24] and Siebers's equations [25] or empirical equations proposed by Hiroyasu et al. [26]. These equations are well known and proved to be accurate enough for simulation, however, they only satisfy the diesel spray propagation during injection with steady state and do not involve any information for that after EOI. Indeed, because of the end of injection, the spray is transformed from the steady state into the deceleration state that leads to the spray propagation different from that in the steady state. Recently, the analytical research was performed on the turbulent jets behaviors during the deceleration state based on the data of some fundamental studies including air jets and water jets [20]. The results showed that the jet deceleration state travels from the nozzle to the jet downstream with an increase in entrainment rate, and the author proposed "entrainment wave" to describe the propagation of the increased entrainment region, which also presents the propagation of information of the fuel injection termination. And the jet penetration shifts from a relation of square-root dependence on time to a relation of fourth-root dependence on time after the entrainment wave arrives at the tip of jet. The former relation is widely proved in steady jet and the later relation is same as the result from the experimental research on unsteady turbulent 
jets [19]. The entrainment wave was predicted in diesel spray based on a one-dimensional discrete spray model and validated by several experimental data [21]. Penetration was also calculated using this model, and the results revealed that the penetration is smaller than that of steady spray after the entrainment wave reaches the spray tip. These indicate that the one-dimensional discrete spray model in [21] has potential to predict the diesel spray propagation after EOI. Thus, a zero-dimensional model of diesel spray propagation was developed based on this one-dimensional discrete spray model to involve the spray information of penetration and air entrainment rate after EOI in this study. To conduct this work, the same assumptions as in the onedimensional discrete spray model in [21] were employed in this study. They are simply reported as follows:

(1) The diesel spray is assumed as a non-vaporizing and incompressible flow.

(2) Turbulent viscous forces in the spray are neglected.

(3) The effects of molecular and turbulent diffusion are ignored.

(4) The net force due to any axial pressure gradient is assumed negligible.

(5) The spray has a conical shape with a constant spreading angle.

(6) The radial profile of mean axial velocity remains unchanged during and after injection.

As for the sixth assumption, a factor $\beta$ was derived in $[20,21]$ to consider the radial profiles of axial velocity and fuel volume fraction, and the value of $\beta$ ranges from 1.0 for a uniform profile to 2.0 for a fully developed spray. In this study, $\beta$ is introduced to represent the axial velocity profile over the tip crosssectional area.

In addition, the entrained air is assumed to mix with injected fuel immediately and homogeneously, and the spray is treated to be formed with a constant injection rate to simplify the spray modeling.

\subsubsection{Spray tip penetration}


According to the entrainment wave theory, the spray tip penetration can be divided into two stages by the transition timing, which is the timing when the entrainment wave arrives at the spray tip.

Before the transition timing, the momentum flux and fuel mass flow rate integrated over the tip crosssectional area $\left(\dot{M}_{\text {tip }}\right.$ and $\left.\dot{m}_{\mathrm{f}, \text { tip }}\right)$ are constant due to the steady state, and the ratio of them is equal to the fuel velocity at the nozzle exit $\left(u_{\mathrm{f}}\right)$ based on the momentum theory $[21,24,25]$.

$\frac{\dot{M}_{\text {tip }}}{\dot{m}_{\text {f,tip }}}=u_{\mathrm{f}}$.

Considering the effect of the radial profile of axial velocity on the momentum flux integrated over the tip cross-sectional area, the $\dot{M}_{\text {tip }}$ is expressed as follows,

$\dot{M}_{\text {tip }}=\rho_{\text {tip }} \beta A_{\text {tip }} \bar{u}_{\text {tip }}^{-2}$

where $\rho_{\text {tip }}$ is the average density in the tip cross-section, $A_{\text {tip }}$ is the tip cross-sectional area, and $\bar{u}_{\text {tip }}$ is the average velocity over the tip cross-section. And the mixture mass flow rate integrated over the tip crosssectional area $\left(\dot{m}_{\text {tip }}\right)$ is

$\dot{m}_{\text {tip }}=\rho_{\text {tip }} A_{\text {tip }} \bar{u}_{\text {tip }}$.

Therefore the spray tip velocity ( $\left.u_{\text {tip }}\right)$ can be obtained as the ratio of equation (2) and (3),

$u_{\text {tip }}=\frac{\dot{M}_{\text {tip }}}{\dot{m}_{\text {tip }}}=\beta \bar{u}_{\text {tip }}$.

In addition, substituting equation (2) into (1), the $\bar{u}_{\text {tip }}$ can be derived as

$\bar{u}_{\text {tip }}=\frac{\dot{m}_{\mathrm{f} \text { tip }} u_{\mathrm{f}}}{\rho_{\text {tip }} \dot{V}_{\text {spray }}}$, 
where $\dot{m}_{\mathrm{f} \text {,tip }}$ is the fuel mass flow rate integrated over the tip cross-sectional area and is equal to the injection rate of fuel mass $\left(\dot{m}_{\mathrm{f}}\right)$, and $\dot{V}_{\text {spray }}$ is the growth rate of spray volume and expressed as follows,

$\dot{V}_{\text {spray }}=\beta \bar{u}_{\text {tip }} A_{\text {tip }}$.

Introducing the variable $\bar{X}_{\mathrm{f} \text {,tip }}$, the average fuel volume fraction over cross-section at the spray tip, which is represented as equation (7),

$$
\bar{X}_{\mathrm{f}, \text { tip }}=\frac{\dot{m}_{\mathrm{f}, \text { tip }} / \rho_{\mathrm{f}}}{\dot{V}_{\text {spray }}},
$$

where $\rho_{\mathrm{f}}$ is the liquid fuel density, then the equation (5) is rewritten as,

$$
\bar{u}_{\text {tip }}=\frac{\rho_{\mathrm{f}} \bar{X}_{\mathrm{f}, \text { tip }} u_{\mathrm{f}}}{\rho_{\text {tip }}},
$$

as well as the average density in the tip cross-section $\left(\rho_{\text {tip }}\right)$ can be calculated by following equation according to [21],

$$
\rho_{\text {tip }}=\rho_{\mathrm{f}} \bar{X}_{\mathrm{f}, \text { tip }}+\rho_{\mathrm{a}}\left(1-\bar{X}_{\mathrm{f}, \text { tip }}\right)
$$

So far the spray tip velocity $\left(u_{\text {tip }}\right)$ is able to be calculated based on the equation from (4) to (9), so that the spray tip penetration $\left(S_{\text {tip }}\right)$ can be obtained by

$$
S_{\text {tip }}=\beta \int_{0}^{t} \frac{\rho_{\mathrm{f}} \bar{X}_{\mathrm{f}, \mathrm{tip}} u_{\mathrm{f}}}{\rho_{\text {tip }}} d t .
$$

The equation (1) is valid also for the period after the transition timing (see Appendixes). Therefore, the same form as the equation (8) is available for the average velocity over the tip cross-section, where $\bar{X}_{\mathrm{f}, \text { tip }}$ and $\rho_{\text {tip }}$ are replaced by those after the transition timing, $\bar{X}_{\text {f,tip,atr }}$ and $\rho_{\text {tip,atr }}$ (equation (11)). 
$\bar{u}_{\text {tip,atr }}=\frac{\rho_{\mathrm{f}} \bar{X}_{\mathrm{f}, \mathrm{tip}, \mathrm{atr}} u_{\mathrm{f}}}{\rho_{\text {tip,atr }}}$,

where $\rho_{\text {tip,atr }}$ is calculated by the equation (9), in which $\bar{X}_{\text {f,tip }}$ is replaced by $\bar{X}_{\text {f,tip,atr }}$. The spray tip penetration after transition timing can gbe calculated as

$S_{\text {tip }}=S_{\text {tip }, \text { tr }}+\beta \int_{t_{\text {tr }}}^{t} \frac{\rho_{\mathrm{f}} \bar{X}_{\mathrm{f}, \text { tip }, \text { atr }} u_{\mathrm{f}}}{\rho_{\text {tip,atr }}} d t$

where $S_{\text {tip,tr }}$ is a penetration at the transition timing. $\bar{X}_{\text {f,tip,atr }}$ is determined as follows to mimic the spray penetrations calculated using the one-dimensional discrete spray model [21].

Figure 2 qualitatively illustrates the variation of air volume and fuel volume in a spray, which is expressed as the area of "Air" region and "Fuel" region, along the spray axial position for the time of $t$ and $t+\Delta t$. The fuel mass flow rate at the tip is constant during the steady state, and the volumetric flow rate at the tip, $\dot{m}_{\mathrm{f}} / \rho_{\mathrm{f}}$, is equal to that at the nozzle exit as shown in Fig. 2 (a). However, after the transition timing the fuel volumetric flow rate decreases from its initial value in the steady state because the information of fuel injection termination already arrived at the spray tip [20]. To describe this process, the volumetric flow rate, $\dot{m}_{\mathrm{f}} / \rho_{\mathrm{f}}$, was assumed to be shared by fuel and air for the period after the transition timing. Based on this assumption, as shown in Fig. 2 (b), part of air flows into "Fuel" region from "Air" region and mixes with fuel, so that the "Fuel" region for the steady state is replaced by the "Fuel+air" region after transition timing, and then the mixture of "Fuel+air" region flows out through the tip with the volumetric flow rate of $\dot{m}_{\mathrm{f}} / \rho_{\mathrm{f}}$. Considering the "Fuel+air" region at time " $t$ " $\left(t>t_{\mathrm{tr}}\right)$ as the control volume, the fluid of "Fuel+air" flows out of the control volume from tip cross-section with the volumetric flow rate of $\dot{m}_{\mathrm{f}} / \rho_{\mathrm{f}}$, while air will flow into the control volume from the "Air" region with the same volumetric flow rate to compensate the outflow due to 
the fluid continuity. Therefore, at any time " $t$ " after transition timing, the total volume of air flow into "Fuel+air" region is $\left(\dot{m}_{\mathrm{f}} / \rho_{\mathrm{f}}\right) \cdot\left(t-t_{\mathrm{tr}}\right)$. For simplicity, it is assumed that the air and fuel mix with each other immediately in the "Fuel + air" region. Then the fuel volume fraction in the fluid flowing out of the "Fuel+air" region from the tip is equal to the average fuel volume fraction in the "Fuel+air" region $\left(X_{\mathrm{f}, \mathrm{fm}}\right)$ and calculated by the following equation,

$X_{\mathrm{f}, \mathrm{fm}}=\frac{\dot{m}_{\mathrm{f}} t_{\mathrm{j}} / \rho_{\mathrm{f}}}{\dot{m}_{\mathrm{f}} t_{\mathrm{j}} / \rho_{\mathrm{f}}+\left(\dot{m}_{\mathrm{f}} / \rho_{\mathrm{f}}\right) \cdot\left(t-t_{\mathrm{tr}}\right)}$,

where $t_{\mathrm{j}}$ is the injection duration, $t_{\mathrm{tr}}$ the transition timing, and $t$ the time from the injection start. Finally $X_{\mathrm{f}, \text { tip,atr }}$ is derived as

$\bar{X}_{\mathrm{f}, \mathrm{tip} \text {,atr }}=\frac{X_{\mathrm{f}, \mathrm{fm}} \dot{m}_{\mathrm{f}} / \rho_{\mathrm{f}}}{\dot{V}_{\text {spray }}}$.

\subsubsection{Air entrainment rate}

Based on the spray tip penetration calculation, the spray volume $\left(V_{\text {spray }}\right)$ can be obtained as a cone volume calculation,

$V_{\text {spray }}=\frac{1}{3} \pi\left[S_{\text {tip }} \tan \left(\frac{\alpha}{2}\right)\right]^{2} S_{\text {tip }}$

where $\alpha$ is the spray spreading angle. Furthermore, according to equation (3) and (6), the air entrainment rate $\left(\dot{m}_{\mathrm{a}}\right)$ can be obtained as

$\dot{m}_{\mathrm{a}}=\left\{\begin{array}{ll}\rho_{\mathrm{a}}\left(\dot{V}_{\text {spray }} / \beta-\dot{m}_{\mathrm{f}} / \rho_{\mathrm{f}}\right) & \left(0<t \leq t_{\mathrm{j}}\right) \\ \rho_{\mathrm{a}} \dot{V}_{\text {spray }} / \beta & \left(t>t_{\mathrm{j}}\right)\end{array}\right.$,

\subsubsection{Spray tail penetration}


After EOI, the mixture near the injector tip becomes very lean because the fuel supply is terminated and air entrainment rate increases near the injector tip after EOI [20-22]. However, there is no spatial information of fuel distribution in a spray involved in this zero-dimensional spray model. Therefore, the part of the spray near the injector tip is assumed to act as ambient air zone, in other word, the practical spray tail is assumed. Knowing the position of the spray tail, the start time of the interaction with the subsequent spray can be determined. Figure 3 shows the ratio between fuel mass in the region from the injector tip to a downstream position of spray and total injection fuel mass $\left(R_{\mathrm{mf}}\right)$ against time, which is calculated based on the onedimensional discrete spray model in [21]. It is observed that the fuel mass in the region near the injector tip decreases quickly after EOI that is $0.5 \mathrm{~ms}$ after start of injection (ASOI), therefore the part of the spray near the injector tip practically acts as air, and it is reasonable to omit this part of spray and to define the spray's tail. In this study, the spray tail position is determined as a cross section of a spray where $10 \%$ of total fuel is contained up to the injector tip.

\subsection{INTERACTION BETWEEN THE SPRAYS FROM SEQUENT INJECTION STAGES}

The interaction between the sprays from sequent injection stages is caused by the entrainment of the second spray from the first spray after the arrival of the second spray tip at the first spray tail. To mimic this interaction, it is requisite to obtain the amount of the first spray mixture entrained into the second spray.

After the second spray tip touches the first spray tail, the entrainment area of the second spray is divided into two parts by the first spray tail as shown in Fig.4. The ratio of the entrainment rate of these two parts $\left(R_{\mathrm{e}}\right)$ can be obtained as equation (17) with assumptions that these entrainment rates are proportional to the areas of the spray boundary surfaces in the ambient air zone and the first spray zone.

$R_{\mathrm{e}}=C_{\mathrm{e}} \frac{A_{\text {air }}}{A_{\text {spray }}}$, 
where $A_{\text {air }}$ and $A_{\text {spray }}$ is the area of the spray boundary surface in the ambient air zone and the first spray zone respectively. $C_{\mathrm{e}}$ is a coefficient given to describe the difference between the entrainment velocity over the spray boundary surface in the ambient air zone and the first spray zone. However, it is difficult to estimate $C_{\mathrm{e}}$ exactly especially after the end of the second injection. Therefore, $C_{\mathrm{e}}$ is treated as a constant of 1.0 in this study. Based on equation (17) and the total entrainment rate of the second spray, the amount of the first spray mixture entrained into the second spray is obtained.

\section{RESULTS AND DISCUSSION}

\subsection{SPRAY TIP PENETRATION AND ENTRAINMENT}

To validate the zero-dimensional spray model derived above, the diesel sprays tip penetration and entrainment rate in two cases including small and large injection quantities were calculated with constant injection rate respectively, and the calculation conditions are shown in Table. 1 . In particular, $\beta$ is set to 2.0 , which means that the spray is in a fully developed state.

At first, to examine the tendency of spray tip penetration after EOI, the calculated spray tip penetration was compared with the relation of one fourth power dependence on time. The calculation results of spray tip penetration under an injection quantity of $2.5 \mathrm{mg}$ and an injection duration of $0.15 \mathrm{~ms}$ are plotted against the time after SOI in double logarithmic coordinate in Fig. 5. After transition timing of $0.3 \mathrm{~ms}$ that is twice of the injection duration, the slope of the curve is gradually decreasing, and approaches the value of one fourth around $10 \mathrm{~ms}$. These results indicate that the calculation is able to catch the same tendency of the spray tip penetration as that concluded in $[19,20,21]$. And then the results of spray tip penetration and entrainment rate were compared with the results obtained from the one-dimensional discrete spray model in [21]. Fig. 6 and 7 show the results of the cases with injection quantities of $2.5 \mathrm{mg}$ and $25 \mathrm{mg}$ respectively, and they reveal that 
the calculated spray tip penetrations and entrainment rates from the one-dimensional discrete spray model are well fitted by those from the zero-dimensional spray model developed in this study. It indicates that the developed zero-dimensional spray model has ability to predict the spray tip penetration and entrainment rate after EOI.

\subsection{COMBUSTION CALCULATION}

Based on the modeling of spray behaviors after EOI and the interaction between sprays from sequent injection stages in the stochastic combustion model, calculations were performed for simulating the combustion in a single-cylinder diesel test engine with pilot/main two-stage injection. The specifications of test engine are listed in Table 2, and the calculation conditions are listed in Table 3. Heat release rates were calculated from the in-cylinder pressure considering the temperature dependency of specific heat ratios, which is the same method as in the experiments.

\subsubsection{Heat release rate of pilot spray}

Figure 8 shows the effects of pilot injection timing $\left(\theta_{\text {pilot }}\right)$ on the heat release rates of pilot spray for injection quantity $\left(q_{\mathrm{fpilot}}\right)$ of $2 \mathrm{~mm}^{3}$. In addition, the heat release amount of pilot spray affects the thermodynamic properties of ambient air and determines the fuel remained in pilot spray, which leads to the variation of main spray combustion. Therefore the in-cylinder pressure at TDC and amount of heat released up to TDC relative to the total input heat by pilot injection $\left(r_{\mathrm{p}}\right)$, which means the progress of heat release from the pilot spray before the main injection start, are also shown in Fig. 8. From the experimental data (left), it can be found that the total released heat of pilot spray increases as the pilot injection is retarded. However the simulation results (center) reveal almost the same value of total released heat, and even $r_{\mathrm{p}}$ are almost equal to 1.0 which represents that the combustion of pilot spray already ended, so that the simulation is not able to 
capture the effects of pilot injection timing on the pilot spray combustion, moreover, on the main spray combustion. Thus the simulation of the pilot spray combustion needs to be improved.

As shown in the figure, the experimental data show lower heat release rates than those of simulation, especially for the cases of earlier pilot injection timings. This phenomenon is probably caused by slow heat release from the mixture in squish region that has not been considered in this model. The early injection timing makes the spray flow into the squish region and impinge on the cylinder liner or piston top as shown in Fig. 9. Due to the low temperature of the walls and/or the adherence of fuel on the piston top surface, oxidation reactions and mixing in the mixture are attenuated. Thus the earlier pilot injection timing obtains the lower heat release. To involve such effects in the combustion model, the fuel-air mixing rate was reduced according to the volume ratio of the spray flowed into the squish area and total spray. The temperature effect mentioned above was not considered, however, the overall oxidation reaction rate is lowered as a result of reduced mixing rate. As shown in Fig. 9, if the spray tip cross-sectional area impinges on the bowl lip edge, the spray can be divided into two parts, the squish part and the bowl part. Thus the volume ratio between squish part and incremental spray $\left(R_{\text {sq,inc }}\right)$ can be calculated as

$R_{\mathrm{sq}, \mathrm{inc}}=\frac{C(\delta) A_{\mathrm{up}}}{C(\delta) A_{\mathrm{up}}+A_{\mathrm{bl}}}$,

where $A_{\mathrm{up}}$ and $A_{\mathrm{bl}}$ are the areas of the cross section at the impinging time over and below the bowl lip edge respectively, and the $C(\delta)$ is a function of the angle between the spray central line and cylinder head, and it is used to describe the ratio between spray spreading velocity in the squish and bowl regions. This function is selected as $\cot \delta$ in this study, because it represents the ratio of the horizontal and vertical components of average spray tip velocity when the piston top is treated as the horizontal area. Sequentially, the volume ratio of the spray flowed into squish region and total spray $\left(R_{\mathrm{sq}}\right)$ can be obtained as 
$R_{\mathrm{sq}}=\frac{\int_{t_{\text {im }}}^{t} R_{\mathrm{sq}, \text { inc }} \dot{\mathrm{spray}}_{\mathrm{s}} d t}{V_{\text {spray }}}$,

where $t_{\mathrm{im}}$ is the impinging time and $V_{\text {spray }}$ is the total spray volume. The stochastic collision frequency $(\omega)$ that represents the turbulent mixing rate is calculated as follows,

$\omega=\omega_{0}\left(1-C_{\mathrm{m}} R_{\mathrm{sq}} G_{\mathrm{j}}^{x}\right)$,

where $C_{\mathrm{m}}$ is a constant, $\omega_{0}$ is the collision frequency of free spray of which calculation can be found in [1012 ], and $G_{\mathrm{j}}$ is the total turbulence energy generated by injection. $G_{\mathrm{j}}$ is used with minus power $(x)$, because the larger turbulence energy generated by injection causes the stronger mixing (larger $\omega$ ). Figure 10 shows the effects of pilot injection quantity on pilot spray's heat release rates and pressures with different values of $x$ and $C_{\mathrm{m}}$ of 1.0 for a pilot injection timing of $-24^{\circ} \mathrm{ATDC}$. From the heat release rates, it can be found that increasing the absolute value of $x$ leads to notable enhancement of mixing rate in the case of larger pilot injection quantity. However, the increase of the absolute value of $x$ also causes too fast combustion compared to the experimental data. Meanwhile the heat release rate and pressure with $x$ of 0 for the pilot injection quantity of $2 \mathrm{~mm}^{3}$ are similar with those of experiment, while the heat release rate and pressure for the case of larger pilot injection quantities are much lower than those of experiment. According to the monotonous increase of mixing rate along with the absolute value of $x$, it can be deduced that there is no proper absolute value of $x$, including the values from 0 to 0.1 , which could make the heat release rates and pressures for different pilot injection quantities be coincident with the measurements. It implies that only adjusting the absolute value of $x$ is not able to obtain reasonable results. Therefore $C_{\mathrm{m}}$ is increased to decrease the mixing rate and consequently decrease the combustion rate. As a reference, $C_{\mathrm{m}}$ is chosen in combination with $x$ to obtain the similar heat release rate and pressure with those of experimental data in the case of pilot injection 
quantity of $2 \mathrm{~mm}^{3}$. The results with different values of $x$ and relevant $C_{\mathrm{m}}$ for a pilot injection timing of $-24^{\circ}$ ATDC are shown in Fig.11. Finally the 6.2 and -0.2 was selected for $C_{\mathrm{m}}$ and $x$ to represent the change in pilot spray's heat release rates and pressures when varying pilot injection quantities.

Consequently, the fuel-air mixing rate is related to the volume ratio $\left(R_{\mathrm{sq}}\right)$ with inverse relation. Therefore, after the modification, the fuel-air mixing rate in the pilot spray is slower than that before modification in the case of early pilot injection timing, which is observed in Fig. 12 and 13. These two figures show the PDF histories of equivalence ratio $(\phi)$ before and after the modification for $q_{\mathrm{fpilot}}=2 \mathrm{~mm}^{3}$ and $\theta_{\text {pilot }}=-19^{\circ}$ ATDC. Compared with the case before the modification in Fig. 12, the lower PDF in lean side $(\phi<0.5)$ shown in Fig. 13 indicates the lower rate of mixture formation. As a result, the combustion rate is decreased, which is revealed as the lower PDF of ignited mixture (mixture which has an equilibrium flame temperature), and it leads to the slower heat release. In addition, according to the equations (18) and (19), $R_{\mathrm{sq}}$ increases with advancing the pilot injection timing, so that the earlier pilot injection timing causes the slower fuel-air mixing rate in the case of constant pilot injection quantity. Thus the slower heat release of pilot spray can be obtained from the calculation when the pilot injection timing is advanced. As shown in Fig. 8 (right), the calculation results after the modification reveal the trends similar to those in experimental data.

\subsubsection{Heat release rate after main injection}

After the above modification, calculations were performed for combustion with pilot/main two-stage injection. The effects of pilot injection timing on heat release rate with pilot injection quantity of $2 \mathrm{~mm}^{3}$ are shown in Fig. 14 (the second graph). The ignition timings are well predicted, however, the peaks of heat release rates during mixing-controlled combustion phase are lower and later than those of experiments. To analyze the reason, the detailed information of the case with the pilot injection timing of $-19^{\circ}$ ATDC are shown in Fig. 15 and 17. Fig. 15 shows the PDF history of equivalence ratio, which indicates that most of the 
mixture has been ignited at $8^{\circ} \mathrm{ATDC}$, so that the combustion hereafter is controlled by the fuel-air mixing. On the other hand, the air entrainment rate of main spray against crank angle is revealed in Fig. 16 (upper), which is represented by the number of air elements entrained into the main spray in a time step of calculation $\left(N_{\mathrm{ae}}\right)$. From this figure, the air entrainment rate is observed to be at a low level and decrease from $8^{\circ}$ ATDC to $12^{\circ}$ ATDC due to the interaction between the main spray and the pilot spray. It results in slow formation of combustible mixture, which is indicated as a lower peak of PDF in lean side, thereby, as shown in Fig.16 (bottom), the heat release rate is lower compared with the period after $12^{\circ} \mathrm{ATDC}$, when the air entrainment rate increases because all of the pilot spray is entrained into the main spray. Thus the air entrainment rate should be enhanced during the interaction between the main spray and the pilot spray.

To solve this problem, the effect of spray wall impingement on air entrainment was included in the model. It is reasonable to consider the enhancement of air entrainment at least in the initial stage of wall impingement (around $3^{\circ}$ ATDC). Thus a constant $\left(C_{\mathrm{ETRM}}\right)$ is given to multiply the air entrainment rate of free spray after the wall impinging. The results with $C_{\text {ETRM }}$ of 1.5 and 2.0 are shown in Fig. 14 (the third and fourth graphs). It can be found that the peaks of heat release rates during mixing-controlled combustion phase become closer to the peaks of heat release rates during premixed combustion phase and higher with increasing $C_{\text {ETRM }}$. Especially for the case of $C_{\mathrm{ETRM}}=2.0$, the heat release rates shows similar curves with experiment. At the same time, the higher peak of PDF shown in Fig. 17 relative to that shown in Fig. 15 indicates that the mixing rate is increased by enhanced the entrainment rate.

\subsubsection{Heat release rate during late combustion period}

Another discrepancy between calculation and measurement is found in the later part of heat release rate. The calculated heat release rate decreases more rapidly than in the measurements as shown in Fig. 14 (bottom and upper). This is because the high entrainment rate even in the late combustion period makes combustion 
end early, so that the heat release rate decreases rapidly. Unlike the case of a single spray, the interaction between the adjacent sprays decreases the entrainment area of the spray; thereby the entrainment rate is suppressed. Thus the ratio of the total spray volume and the chamber volume was used to represent the intensity of the interaction between adjacent sprays, and the interaction effect on entrainment rate is introduced as follows,

$\dot{m}_{\mathrm{ad}}=\dot{m}_{\mathrm{a} 0}\left(1-C_{\mathrm{vr}} \frac{V_{\text {spray }} \times n_{\text {hole }}}{V_{\text {cyl }}}\right)$,

where $\dot{m}_{\mathrm{ad}}$ is the air entrainment rate affected by spray-volume increase, $\dot{m}_{\mathrm{a} 0}$ is the original air entrainment rate, $n_{\text {hole }}$ is the number of nozzle holes, $V_{\text {cyl }}$ is the volume in cylinder, and $C_{\mathrm{vr}}$ is a constant to fit the experiment data. Considering that the suppression of air entrainment due to this mechanism would be prominent after the end of injection, the equation (21) is applied after the transition timing, because the entrainment rate of spray starts to decrease after this timing. In addition, the entrainment wave starts from the injection speed deceleration, and the transition duration is defined as twice of the duration from the start of injection to entrainment wave start timing [20]. Thus the transition timing $\left(t_{\mathrm{tr}}\right)$ is decided as

$t_{\mathrm{tr}}=2 C_{\mathrm{EW}} t_{\mathrm{j}}$,

where the constant of $C_{\mathrm{EW}}$ is set to the value from 0 to 1 multiplying the injection duration to represent the timing when entrainment wave starts, and it is taken as 0.52 according to the injection rate.

Figure 18 shows the comparison of the entrainment rate of main spray and the heat release rate before and after the modification for $q_{\text {fpilot }}=2 \mathrm{~mm}^{3}$ and $\theta_{\text {pilot }}=-19^{\circ}$ ATDC. In the figure (upper), the entrainment rates of main spray are indicated by the number of fluid elements entrained into the main spray in a time step of calculation $\left(N_{\mathrm{e}}\right)$. It can be observed that before modifications $\left(C_{\mathrm{ETRM}}=2.0\right)$ the main spray entrains all the air elements in the combustion chamber up to $11.5^{\circ} \mathrm{ATDC}$. And because the $C_{\mathrm{EW}}$ is selected as 0.52 and the main 
injection duration is $9.6^{\circ} \mathrm{CA}$ for the case with $q_{\mathrm{fpilot}}=2 \mathrm{~mm}^{3}$, the transition timing is equal to $11^{\circ}$ ATDC based on equation (22). It implies that there is almost no air elements remained after the transition timing, which makes the equation (21) lose its efficacy. Thus the $C_{\text {ETRM }}$ is set to 1.5 with which the peaks of heat release rates during mixing-controlled combustion phase are not reduced significantly as shown in Fig. 14, and the peaks of heat release rates during mixing-controlled combustion phase can be advanced to the transition timing due to the rapid decrease of entrainment rate caused by equation (21) as shown in Fig. 18 in the cases after modification with $C_{\mathrm{vr}}=0.4,0.8$, and 1.0 .

In addition, as expressed in equation (21), the entrainment rate is decreased with increasing the value of $C_{\mathrm{vr}}$. This tendency can be observed in the Fig. 18 (upper) with the cases after modification, and smaller $C_{\mathrm{vr}}$ leads to earlier consumption of air elements. From the Fig. 18 (below), it is observed that the $C_{\mathrm{vr}}$ affects the heat release rate during late combustion period while it does not influence the heat release rate before the peak of heat release rate during mixing-controlled combustion phase. The heat release rate during late combustion period is elevated with increasing the value of $C_{\mathrm{vr}}$ (from 0.4 to 0.8 ), however, too large $C_{\mathrm{vr}}\left(C_{\mathrm{vr}}=1.0\right)$ leads to lower heat release rate during late combustion period due to too low entrainment rate. Thus the $C_{\mathrm{vr}}$ is selected as 0.8 to fit the heat release rate during late combustion period.

Finally, based on all of the improvements and selected constants above, the calculation was performed with different pilot injection quantities $\left(q_{\text {fpilot }}=2,4,6 \mathrm{~mm}^{3}\right)$ and timings $\left(\theta_{\text {pilot }}=-9^{\circ},-19^{\circ},-24^{\circ}\right.$ ATDC), the results of heat release rate are shown in Fig. 19. It reveals that the model can obtain the similar heat release rate shape for each case, and it also can capture the same tendencies of the heat release rate when the pilot injection timing and quantity are varied.

\section{CONCLUSIONS}


In this study, the stochastic combustion model was modified by introducing the submodels including spray propagation and the interaction between sprays from sequent injection stages to realize the simulation of the combustion with multi-stage injection. Especially, the spray propagation model was developed for zerodimensional calculation with attention to spray penetration and entrainment after EOI and validated based on the one-dimensional discrete spray model in [21] . And then the simulation of combustion was conducted on a single-cylinder diesel engine with pilot/main two-stage injection. Based on analyzing the results of heat release rate, entrainment rate, and PDF of equivalence ratio, the fuel-air mixing rate and entrainment rate were modified by considering the effects of wall impingement and adjacent sprays interaction to improve the accuracy of the combustion model. And the primary conclusions for combustion modeling with spray behaviors effects are summarized as follows,

1. The developed combustion model has capability to accurately predict the ignition and combustion characteristics of diesel engine with pilot/main two-stage injection.

2. Based on comparison with the one-dimensional discrete spray model in [21], the zero-dimensional spray model proposed in this study is able to predict the evolutions of diesel spray penetration and overall entrainment rate even after the end of injection.

3. Reduction of fuel-air mixing rate by spray flowed into squish region after wall impingement should be considered for simulating the combustion in the pilot injection case to capture the decrease of heat release with advancing pilot injection timing.

4. The enhancement of main spray entrainment rate by wall impingement is effective to reproduce the heat release rate during the initial period of mixing-controlled combustion phase.

5. Considering the effects of adjacent sprays interaction on suppression of entrainment rate has potential to obtain more accurate heat release rate during late combustion period. 


\section{REFERENCES}

[1] Pierpont, D. A., Montgomery, D. T., and Reitz, R. D. Reducing particulate and NOx using multiple injections and EGR in a DI diesel engine. SAE paper 950217,1995.

[2] Chen, S. K. Simultaneous reduction of NOx and particulate emissions by using multiple injections in a small diesel engine. SAE paper 2000-01-3084, 2000.

[3] Badami, M., Mallamo, F., Millo, F., et al. Influence of multiple injection strategies on emissions, combustion noise and BSFC of a DI common rail diesel engine. SAE paper 2002-01-0503, 2002.

[4] Hotta, Y., Inayoshi, M., Nakakita, K., et al. Achieving lower exhaust emissions and better performance in an HSDI diesel engine with multiple injection. SAE paper 2005-01-0928, 2005.

[5] Vanegas, A., Won, H., Felsch, C., et al. Experimental investigation of the effect of multiple injections on pollutant formation in a common-rail DI diesel engine. SAE paper 2008-01-1911, 2008.

[6] Hiroyasu, H., Kadota, T., and Arai, M. Development and use of a spray combustion modeling to predict diesel engine efficiency and pollutant emissions: Part 1 combustion modeling. Bulletin of JSME 1983, 26, 569-575.

[7] Barba, C., Burkhardt, C., Boulouchos, K., et al. A phenomenological combustion model for heat release rate prediction in high speed DI diesel engines with common rail injection. SAE paper 2000-01-2933, 2000.

[8] Lakshminarayanan, P. A., Aghav, Y. V., Dani, A. D., et al. Accurate prediction of the rate of heat release in a modern direct injection diesel engine. Proc. IMechE, Part D: J. Automobile Engineering, 2002, 216, 663-675.

[9] Chmela, F. G. and Orthaber, G. C. Rate of heat release prediction for a direct injection diesel engine based on purely mixing controlled combustion. SAE paper 1999-01-0186, 1999. 
[10] Ikegami, M., Shioji, M., and Koike, M. A stochastic approach to model the combustion process in direct-injection diesel engines. In: Twentieth Symp. (Int.) on Combustion, 1984, pp.217-224.

[11] Ishiyama, T., Shioji, M., and Ihara, T. Analysis of ignition processes in a fuel spray using an ignition model including turbulent mixing and reduced chemical kinetics. Int. J. Engine Res, 2003, 4, 155-162.

[12] Ishiyama, T., Kee, S. S., and Kitamura, Y. Modeling and experiment of NOx formation in DI-PCCI combustion. SAE paper 2007-01-0194, 2007.

[13] Horibe, N. and Ishiyama, T. Study on selection of injection conditions for diesel PCCI combustion: Numerical investigation using an ignition-combustion model based on stochastic approach. Trans. JSME(B), 2010, 76, 699-706. (In Japanese).

[14] Yao, M., Zheng, Z., and Liu, H. Progress and recent trends in homogeneous charge compression ignition (HCCI) engines. Prog. Energy Combust. Sci, 2009, 35, 398-437.

[15] Siewert, R. M. A Phenomenological engine model for direct injection of liquid fuels, spray penetration, vaporization, ignition delay and combustion. SAE paper 2007-01-0673, 2007.

[16] Inagaki, K., Ueda, M., Mizuta, J., et al. Universal diesel engine simulator (UniDES): $1^{\text {st }}$ report: phenomenological multi-zone PDF model for predicting the transient behavior of diesel engine combustion. SAE paper 2008-01-0843, 2008.

[17] Dulbecco, A. and Lafossas, F. A. A OD phenomenological approach to model diesel HCCI combustion with multi-injection strategies using probability density functions and detailed tabulated chemistry. SAE paper 2009-01-0678, 2009.

[18] Nicolas, B., Christian, C., and Pascal, H. A physical 0D diesel combustion model using tabulated chemistry with presumed probability density function approach: for engine pre-mapping. In: FISITA world automotive congress, Budapest, Hungary, 30 May-4 June 2010, FISITA 2010-SC-O-26. 
[19] Sangras, R., Kwon, O. C., and Faeth, G. M. Self-preserving properties of unsteady round nonbuoyant turbulent starting jets and puffs in still fluids. J. Heat Transfer, 2002, 124, 460-469.

[20] Musculus, M. P. B. Entrainment waves in decelerating transient turbulent jets. J. Fluid Mech., 2009, 638, 117-140.

[21] Musculus, M. P. B. and Kattke, K. Entrainment waves in diesel jets. SAE paper 2009-01-1355, 2009.

[22] Musculus, M. P. B., Lachaux, T., Pickett, L. M., et al. End-of-injection over-mixing and unburned hydrocarbon emissions in low-temperature-combustion diesel engines. SAE paper 2007-01-0907, 2007.

[23] Moon, S., Matsumoto, Y., and Nishida, K. Entrainment, evaporation and mixing characteristics of diesel sprays around end-of-injection. SAE paper 2009-01-0849, 2009.

[24] Wakuri, Y., Fujii, M., Amitani, T., et al. Studies on the penetration of fuel spray in a diesel engine. Bulletin of JSME, 1960, 3, 123-130.

[25] Naber, J. D. and Siebers, D. Effects of gas density and vaporization on penetration and dispersion of diesel sprays. SAE paper 960034, 1996.

[26] Hiroyasu, H., Kadota, T., and Arai, M. Supplementary comments: fuel spray characterization in diesel engines. In: Mattavi, J. N. and Amann C. A. (eds) Combustion Modeling in Reciprocating Engines. Plenum Press., 1980, pp. 369-408.

[27] Janicka, J., Kolbe, W., and Kollmann, W. Closure of the transport equation for the probability density funcfion of turbulent scalar fields. J. Non-Equilib. Thermodn., 1979, 4, 47-66.

[28] Schreiber, M., Sakak, A. S., and Lingens, A. A reduced thermokinetic model for the autoignition of fuels with variable octane ratings. In: Twenty-fifth Symp. (Int.) on Combustion, 1994, pp.933-940.

[29] Woschni, G. Universally applicable equation for the instantaneous heat transfer coefficient in the internal combustion engine. SAE paper 670931, 1967 


\section{List of Table Captions:}

Table 1 Calculation Conditions of Spray model

Table 2 Standard specifications of test engine

Table 3 Simulation performing conditions

\section{List of Figure Captions:}

Fig. 1 Model's concept diagram

Fig. 2 Fuel and air flow at the spray tip during the steady state and after the transition timing

Fig. 3 Ratio between fuel mass in the region from injector tip to a downstream position of the spray and the total injection fuel mass $\left(R_{\mathrm{mf}}\right)$

Fig. 4 Sprays interaction diagram

Fig. 5 Spray tip penetration tendency (Inj. quantity: $2.5 \mathrm{mg}$, Inj. duration: $0.15 \mathrm{~ms}$ )

Fig. 6 Spray tip penetration and entrainment rate (Inj. quantity: $2.5 \mathrm{mg}$, Inj. duration: $0.15 \mathrm{~ms}$ )

Fig. 7 Spray tip penetration and entrainment rate (Inj. quantity: $25 \mathrm{mg}$, Inj. duration: $0.75 \mathrm{~ms}$ )

Fig. 8 Effects of pilot injection timing on pilot spray's heat release rate, in-cylinder pressure at TDC and the ratio between the amount of heat released up to TDC and the total input heat by pilot injection $\left(r_{\mathrm{p}}\right)$ $\left(q_{\text {fpilot }}=2 \mathrm{~mm}^{3}\right)$

Fig. 9 Wall impingement diagram

Fig. 10 Effects of pilot injection quantity on pilot spray's heat release rates and pressures with different values of $x$ and $C_{\mathrm{m}}$ of $1.0\left(\theta_{\text {pilot }}=-24^{\circ} \mathrm{ATDC}\right)$

Fig. 11 Effects of pilot injection quantity on pilot spray's heat release rates and pressures with different values of $x$ and relevant $C_{\mathrm{m}}\left(\theta_{\text {pilot }}=-24^{\circ}\right.$ ATDC $)$ 
Fig. 12 PDF histories for equivalence ratio of pilot spray before modification on mixing rate $\left(q_{\text {fpilot }}=2 \mathrm{~mm}^{3}\right.$, $\left.\theta_{\text {pilot }}=-19^{\circ} \mathrm{ATDC}\right)$

Fig. 13 PDF histories for equivalence ratio of pilot spray after modification on mixing rate $\left(q_{\mathrm{fpilot}}=2 \mathrm{~mm}^{3}\right.$, $\left.\theta_{\text {pilot }}=-19^{\circ} \mathrm{ATDC}\right)$

Fig. 14 Effects of pilot injection timing on heat release rate with different values of $\mathrm{C}_{\mathrm{ETRM}}\left(q_{\mathrm{fpilot}}=2 \mathrm{~mm}^{3}\right)$

Fig. 15 PDF histories of equivalence ratio with $C_{\mathrm{ETRM}}=1.0\left(q_{\mathrm{fpilot}}=2 \mathrm{~mm}^{3}, \theta_{\text {pilot }}=-19^{\circ} \mathrm{ATDC}\right)$

Fig. 16 Air entrainment rate and heat release rate with $C_{\mathrm{ETRM}}=1.0\left(q_{\mathrm{fpilot}}=2 \mathrm{~mm}^{3}, \theta_{\text {pilot }}=-19^{\circ} \mathrm{ATDC}\right)$

Fig. 17 Histories of PDF for equivalence ratio with $C_{\mathrm{ETRM}}=2.0\left(q_{\text {fpilot }}=2 \mathrm{~mm}^{3}, \theta_{\text {pilot }}=-19^{\circ}\right.$ ATDC $)$

Fig. 18 Entrainment rates and heat release rates before and after modification of entrainment rate decreased by adjacent sprays interaction $\left(q_{\text {fpilot }}=2 \mathrm{~mm}^{3}, \theta_{\text {pilot }}=-19^{\circ}\right.$ ATDC $)$

Fig. 19 Effects of pilot injection timing and injection quantity on the heat release rate $\left(q_{\mathrm{fpilot}}=2,4,6 \mathrm{~mm}^{3}\right.$, $\theta_{\text {pilot }}=-9^{\circ},-19^{\circ},-24^{\circ}$ ATDC)

Fig. A1 Control volume selection for spray tip penetration calculation after transition timing.

\section{List of Notation:}

$A_{\text {air }} \quad$ area of the second spray boundary surface in the ambient air zone

$A_{\mathrm{bl}} \quad$ area of the spray cross section at the impinging time over the bowl lip edge

$A_{\text {spray }} \quad$ area of the second spray boundary surface in the first spray zone

$A_{\text {tip }} \quad$ cross-sectional area at spray tip

$A_{\text {up }} \quad$ area of the spray cross section at the impinging time below the bowl lip edge

ASOI after the start of injection

ATDC after the top dead center

cot cotangent function 
$C_{\mathrm{e}} \quad$ model constant for ratio between the entrainment rates of the second spray in the ambient air zone and the first spray zone

$C_{\mathrm{m}} \quad$ constant for collision frequency affected by spray flowing into squish region

$C_{\mathrm{vr}} \quad$ constant for entrainment rate affected by adjacent sprays interaction

$C_{\text {ETRM }}$ constant for entrainment rate after spray impinging on the wall

$C_{\mathrm{EW}} \quad$ constant for transition timing

$C(\delta) \quad$ function of the angle between the spray central line and cylinder head

DI direct injection

EOI end of injection

$f \quad$ probability density function

$G_{\mathrm{j}} \quad$ total turbulence energy generated by injection

$h \quad$ specific enthalpy

$\dot{m}_{\mathrm{a}} \quad$ spray entrainment rate

$\dot{m}_{\mathrm{a} 0} \quad$ spray entrainment rate without adjacent sprays interaction effect

$\dot{m}_{\text {ad }} \quad$ spray entrainment rate affected by adjacent sprays interaction

$\dot{m}_{\mathrm{f}} \quad$ injection rate of fuel mass

$\dot{m}_{\mathrm{f}, \text { tip }} \quad$ fuel mass flow rate integrated over spray tip cross-sectional area

$\dot{m}_{\text {tip }} \quad$ mixture mass flow rate integrated over spray tip cross-sectional area

$\dot{M}_{\text {tip }} \quad$ momentum flux integrated over spray tip cross-sectional area

$n_{\text {hole }} \quad$ number of nozzle holes 
$N_{\mathrm{ae}} \quad$ number of air elements entrained into the main spray in a time step of calculation

$N_{\mathrm{e}} \quad$ number of fluid elements entrained into the main spray in a time step of calculation

PCCI premixed charge compression ignition

PDF probability density function

$q_{\text {fpilot }} \quad$ pilot injection quantity

$r_{\mathrm{p}} \quad$ amount of heat released up to TDC relative to the total input heat by pilot injection

$R_{\mathrm{e}} \quad$ ratio between the entrainment rates of the second spray in the ambient air zone and the first spray

zone

$R_{\mathrm{mf}} \quad$ ratio between fuel mass in the region from the injector tip to a downstream position of spray and total injection fuel mass

$R_{\text {sq,inc }} \quad$ volume ratio between squish part and incremental spray

$R_{\mathrm{sq}} \quad$ volume ratio of the spray flowed into squish region and total spray

$S_{\text {tip }} \quad$ spray tip penetration

$S_{\text {tip,tr }} \quad$ spray tip penetration at the transition timing

SOI start of injection

$t \quad$ time

tan tangent function

$t_{\mathrm{j}} \quad$ injection duration

$t_{\mathrm{tr}} \quad$ transition timing

TDC top dead center

$u_{\mathrm{f}} \quad$ fuel velocity at the nozzle exit

$u_{\text {tip }} \quad$ spray tip velocity 
$\bar{u}_{\text {tip }} \quad$ average velocity over spray tip cross section before transition timing

$\bar{u}_{\text {tip, atr }}$ average velocity over spray tip cross section after transition timing

$V_{\text {cyl }} \quad$ volume in cylinder

$V_{\text {spray }} \quad$ spray volume

$\dot{V}_{\text {spray }} \quad$ growth rate of spray volume

$x \quad$ a power given to $G_{\mathrm{j}}$

$X_{\mathrm{f}, \mathrm{fm}} \quad$ average fuel volume fraction in the "Fuel+air" region

$\bar{X}_{\mathrm{f}, \mathrm{tip}} \quad$ average fuel volume fraction over cross-section at the spray tip before transition timing

$\bar{X}_{\mathrm{f} \text {,tip,atr }}$ average fuel volume fraction over cross-section at the spray tip after transition timing

$y_{\mathrm{i}} \quad$ mass fraction of chemical species

$z \quad$ thermodynamic states of fluid elements including mass fraction of chemical species and specific enthalpy

$\alpha \quad$ spray spreading angle

$\beta \quad$ factor introduced to consider the radial profiles of axial velocity and fuel volume fraction

$\delta \quad$ angle between the spray central line and cylinder head

$\theta \quad$ crank angle

$\theta_{\text {pilot }} \quad$ pilot injection timing

$\rho_{\mathrm{a}} \quad$ air density

$\rho_{\mathrm{f}} \quad$ liquid fuel density

$\rho_{\text {tip }} \quad$ average density in spray tip cross-section before transition timing

$\rho_{\text {tip,atr }} \quad$ average density in spray tip cross-section after transition timing 
$\phi \quad$ equivalence ratio

$\omega \quad$ collision frequency affected by spray flowing into squish region

$\omega_{0} \quad$ collision frequency of free spray 


\section{APPENDIXES}

To demonstrate the variation of the ratio between momentum flux and fuel mass flow rate integrated over the tip cross-sectional area after the transition timing, the incremental spray volume $\left(\Delta V_{\text {spray }}\right)$ within a short interval $(\Delta t)$ at the spray tip is selected as a control volume, as the shadow region shown in Fig. A1, which is enclosed by the tip cross-sectional areas at the time of $t\left(t \geq t_{\mathrm{tr}}\right)$ and $t+\Delta t$ after start of injection (SOI), and the side surface of the spray cone. At the time of $t$, the momentum and fuel mass flows into the control volume from the upstream cross-sectional area and does not yet flow out from the downstream crosssectional area, so that the momentum $\left(M_{\Delta \mathrm{V}}\right)$ and fuel mass $\left(m_{\mathrm{f}, \Delta \mathrm{V}}\right)$ in this control volume after the interval of $\Delta t$ can be express as the equation (A1) and (A2),

$M_{\Delta \mathrm{V}}=\dot{M}_{\text {tip }}(t) \Delta t$

$m_{\mathrm{f}, \Delta \mathrm{V}}=\dot{m}_{\mathrm{f}, \text { tip }}(t) \Delta t$

where $\dot{M}_{\text {tip }}(t)$ and $\dot{m}_{\mathrm{f}, \text { tip }}(t)$ are integral momentum flux and fuel mass flow rate over the tip cross-sectional area at time of $t$. When the spray propagates just after the time of $t+\Delta t$, the integral momentum flux $\left(\dot{M}_{\text {tip }}(t+\Delta t)\right)$ and fuel mass flow rate $\left(\dot{m}_{\mathrm{f} \text {,ip }}(t+\Delta t)\right)$ over the downstream tip cross-sectional area can be expressed as the equation (A3) and (A4).

$$
\begin{aligned}
& \dot{M}_{\text {tip }}(t+\Delta t)=\beta \bar{\rho}_{\text {tip }}(t+\Delta t)\left[\bar{u}_{\text {tip }}(t+\Delta t)\right]^{2} A_{\text {tip }}(t+\Delta t), \\
& \dot{m}_{\text {f,tip }}(t+\Delta t)=\beta \rho_{\mathrm{f}} \bar{X}_{\text {f,tip }}(t+\Delta t) \bar{u}_{\text {tip }}(t+\Delta t) A_{\text {tip }}(t+\Delta t),
\end{aligned}
$$


where $\bar{\rho}_{\text {tip }}(t+\Delta t)$ is the average density of the mixture in the control volume, $\bar{u}_{\text {tip }}(t+\Delta t)$ is the average velocity over the tip cross-section at the time of $t+\Delta t$, and the $\bar{X}_{\mathrm{f}, \text { tip }}(t+\Delta t)$ is the average volume fraction of fuel in the control volume. Then the ratio of $\dot{M}_{\text {tip }}(t+\Delta t)$ and $\dot{m}_{\mathrm{f}, \text { tip }}(t+\Delta t)$ is presented as

$$
\frac{\dot{M}_{\text {tip }}(t+\Delta t)}{\dot{m}_{\text {f, tip }}(t+\Delta t)}=\frac{\bar{\rho}_{\text {tip }}(t+\Delta t) \bar{u}_{\text {tip }}(t+\Delta t)}{\rho_{\mathrm{f}} \bar{X}_{\text {f,tip }}(t+\Delta t)},
$$

where $\bar{u}_{\text {tip }}(t+\Delta t)$ can be obtained as

$$
\bar{u}_{\text {tip }}(t+\Delta t)=\frac{M_{\Delta \mathrm{V}}}{\bar{\rho}_{\text {tip }}(t+\Delta t) \Delta V_{\text {spray }}}
$$

and $\bar{X}_{\mathrm{f}, \text { tip }}(t+\Delta t)$ is calculated as

$$
\bar{X}_{\mathrm{f}, \text { tip }}(t+\Delta t)=\frac{m_{\mathrm{f}, \Delta \mathrm{V}}}{\rho_{\mathrm{f}} \Delta V_{\text {spray }}} .
$$

According to the equation (A1), (A2), (A6), and (A7), the equation (A5) can be rewritten as

$$
\frac{\dot{M}_{\text {tip }}(t+\Delta t)}{\dot{m}_{\text {f,tip }}(t+\Delta t)}=\frac{\dot{M}_{\text {tip }}(t)}{\dot{m}_{\text {f,tip }}(t)} \text {. }
$$

From the equation (A8), it can be concluded that the ratio of the integral momentum flux and fuel mass flow rate over the tip cross-sectional area at any time after the transition timing is constant and equal to that at the transition timing. It is reasonable to treat the spray still in the steady state at the tip position at the transition timing, so that the value of the ratio is equal to the velocity at the nozzle exit during injection $\left(u_{\mathrm{f}}\right)$, which is expressed as equation (A9).

$\frac{\dot{M}_{\text {tip,atr }}}{\dot{m}_{\text {f,tip,atr }}}=u_{\mathrm{f}}$ 
where $\dot{M}_{\text {tip,atr }}$ and $\dot{m}_{\mathrm{f}, \text { tip,atr }}$ represent the integral momentum flux and fuel mass flow rate over the tip crosssectional area after the transition timing respectively. 
Table 1 Calculation Conditions of Spray model

\begin{tabular}{|l|c|}
\hline Ambient pressure & $4.0 \mathrm{MPa}$ \\
\hline Ambient Temperature & $1015.0 \mathrm{~K}$ \\
\hline Fuel & JIS 2\#, Density: $832.7 \mathrm{~kg} / \mathrm{m}^{3}$ \\
\hline Nozzle diameter & $0.18 \mathrm{~mm} \times 6$ holes nozzle \\
\hline Injection quantity & $2.5 \mathrm{mg}, 25 \mathrm{mg}$ \\
\hline Injection duration & $0.15 \mathrm{~ms}, 0.75 \mathrm{~ms}$ \\
\hline $\begin{array}{l}\text { Ambient gas composition } \\
\text { by volume }\end{array}$ & $\mathrm{O}_{2}: 0.5 \%, \mathrm{~N}_{2}: 87.4 \%, \mathrm{CO}_{2}: 4.8 \%, \mathrm{H}_{2} \mathrm{O}: 7.3 \%$ \\
\hline
\end{tabular}

Table 2 Standard specifications of test engine

\begin{tabular}{|l|c|}
\hline Engine type & Single-cylinder, DI-Diesel engine \\
\hline Bore $\times$ Stroke & $85 \times 96.9 \mathrm{~mm}$ \\
\hline Displacement & $550 \mathrm{cc}$ \\
\hline Compression ratio & 16.3 \\
\hline Combustion chamber & Reentrant type $(\phi 51.6$ cavity $)$ \\
\hline Injection system & $\begin{array}{c}\text { Common-rail system } \\
0.125 \mathrm{~mm} \times 7 \text { holes nozzle }\end{array}$ \\
\hline
\end{tabular}

Table 3 Simulation performing conditions

\begin{tabular}{|l|c|}
\hline Injection pressure & $125 \mathrm{MPa}$ \\
\hline Total injection quantity & $32 \mathrm{~mm}^{3}$ per cycle \\
\hline $\begin{array}{l}\text { Pilot injection quantity } \\
\left(q_{\text {fpilot }}\right)\end{array}$ & $2,4,6 \mathrm{~mm}^{3}$ per cycle \\
\hline $\begin{array}{l}\text { Pilot injection timing } \\
\left(\theta_{\text {pilot }}\right)\end{array}$ & $-9,-19,-24^{\circ}$ ATDC \\
\hline Main injection timing & $1^{\circ}$ ATDC \\
\hline EGR ratio & $20 \%$ \\
\hline Swirl ratio & 2.0 \\
\hline
\end{tabular}




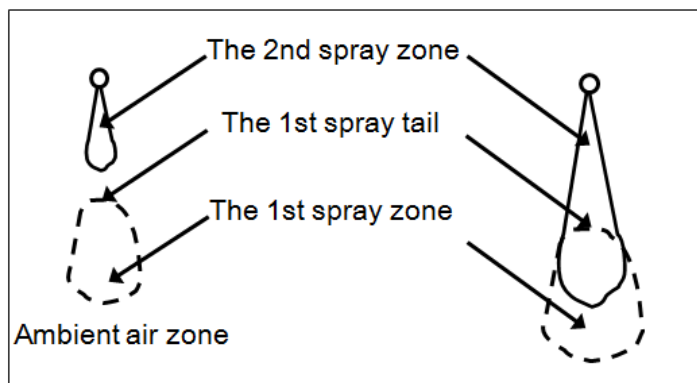

Fig. 1 Model's concept diagram
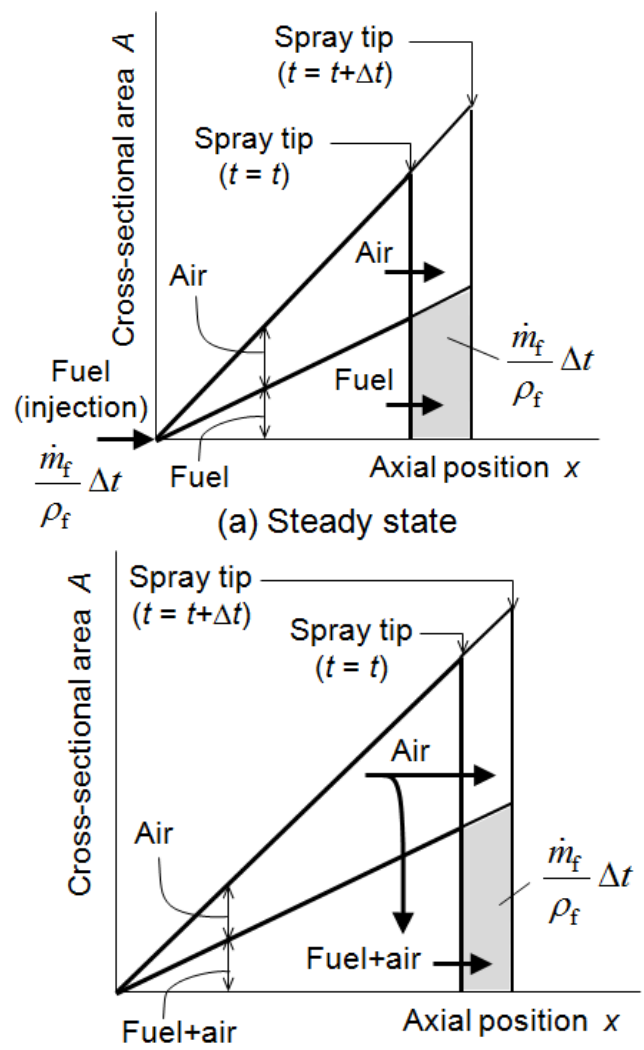

(b) After transition timing

Fig. 2 Fuel and air flow at the spray tip during the steady state and after the transition timing 


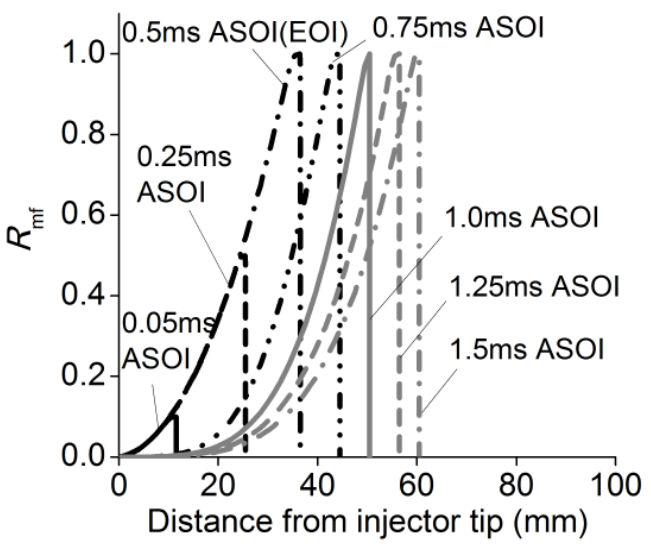

Fig. 3 Ratio between fuel mass in the region from injector tip to a downstream position of the spray and the total injection fuel mass $\left(R_{\mathrm{mf}}\right)$

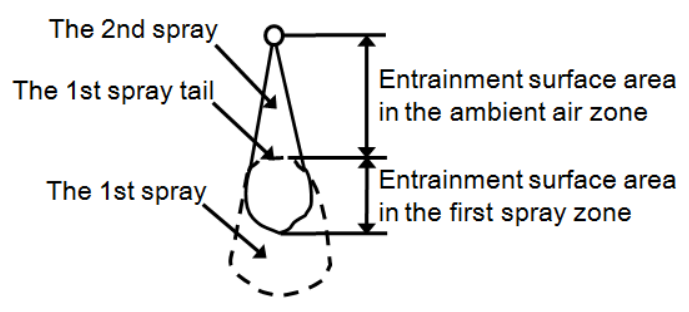

Fig. 4 Sprays interaction diagram

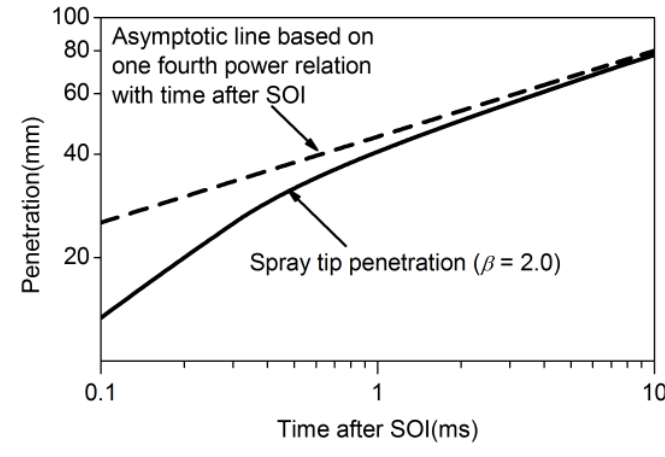

Fig. 5 Spray tip penetration tendency (Inj. quantity: $2.5 \mathrm{mg}$, Inj. duration: $0.15 \mathrm{~ms}$ )

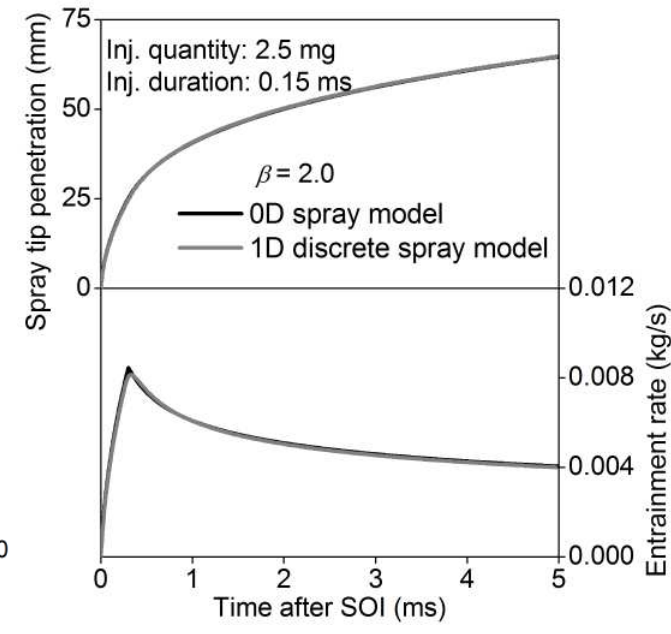

Fig. 6 Spray tip penetration and entrainment rate (Inj. quantity: $2.5 \mathrm{mg}$, Inj. duration: $0.15 \mathrm{~ms}$ ) 


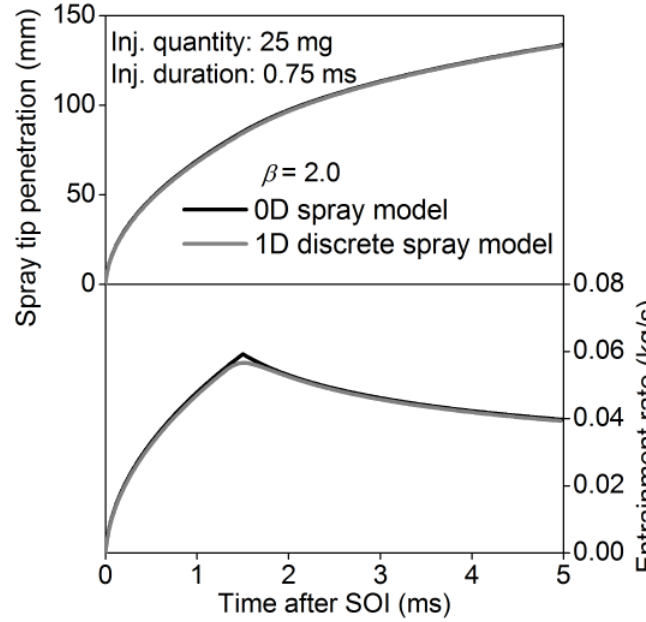

Fig. 7 Spray tip penetration and entrainment rate (Inj. quantity: $25 \mathrm{mg}$, Inj. duration: $0.75 \mathrm{~ms}$ )
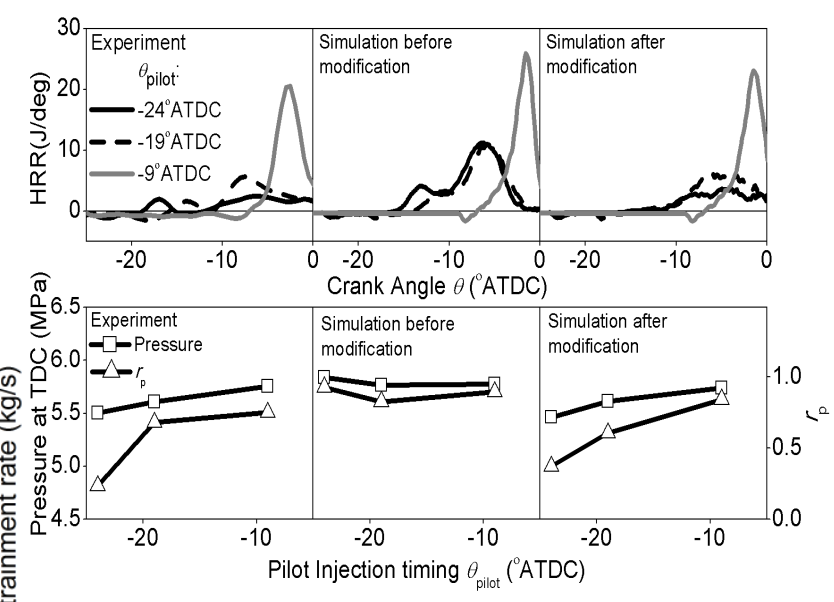

Fig. 8 Effects of pilot injection timing on pilot spray's heat release rate, in-cylinder pressure at TDC and the ratio between the amount of heat released up to TDC and the total input heat by pilot injection $\left(r_{\mathrm{p}}\right)\left(q_{\mathrm{fpilot}}=2 \mathrm{~mm}^{3}\right)$

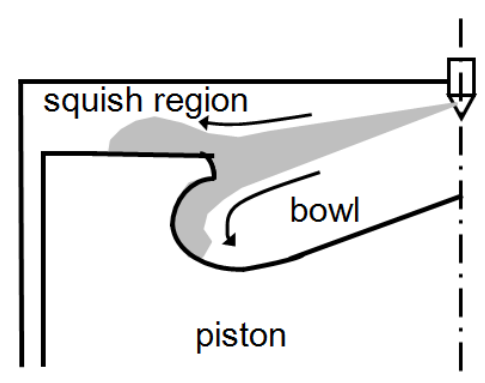

Fig. 9 Wall impingement diagram 


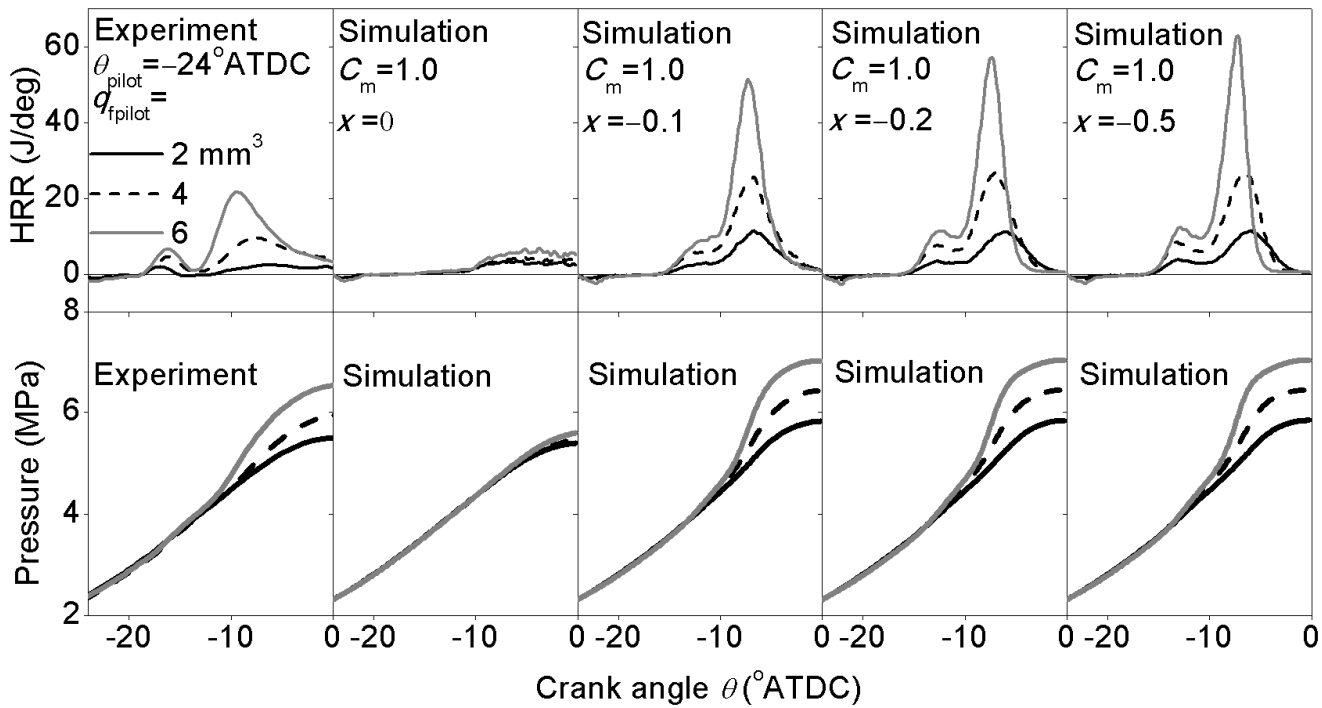

Fig. 10 Effects of pilot injection quantity on pilot spray's heat release rates and pressures with different values of $x$ and $C_{\mathrm{m}}$ of $1.0\left(\theta_{\text {pilot }}=-24^{\circ} \mathrm{ATDC}\right)$

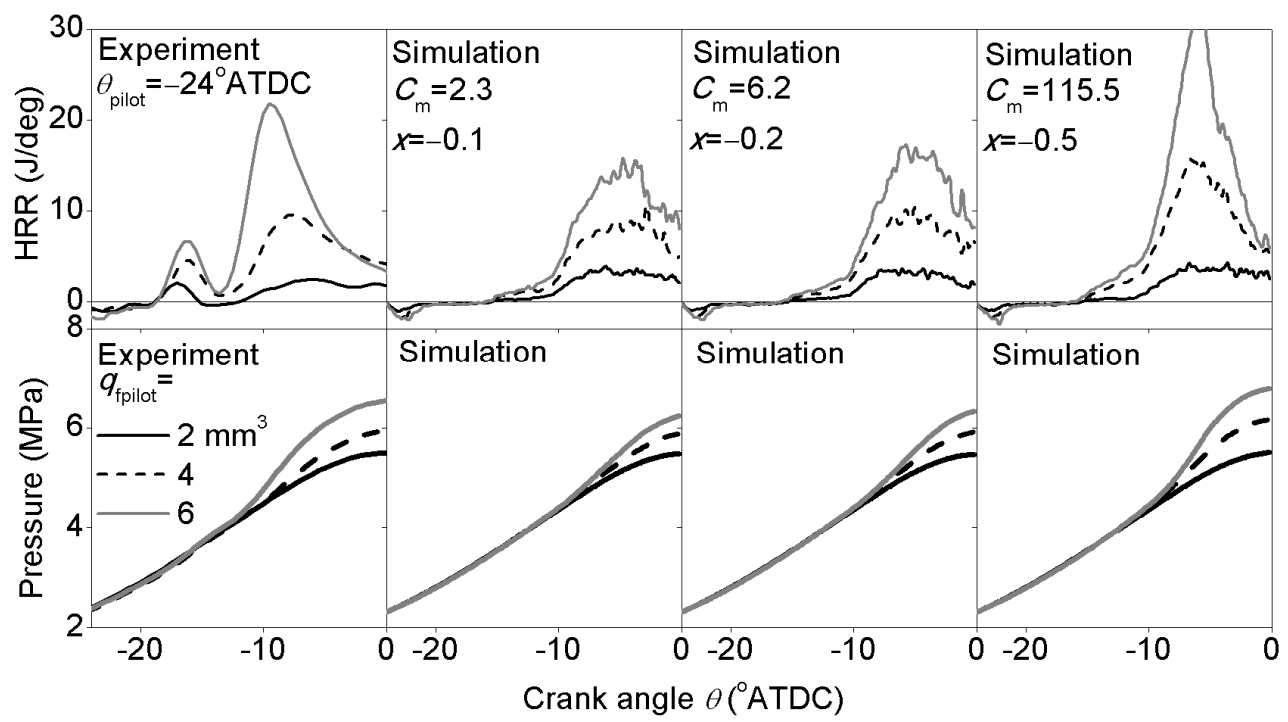

Fig. 11 Effects of pilot injection quantity on pilot spray's heat release rates and pressures with different values of $x$ and relevant $C_{\mathrm{m}}\left(\theta_{\text {pilot }}=-24^{\circ} \mathrm{ATDC}\right)$ 


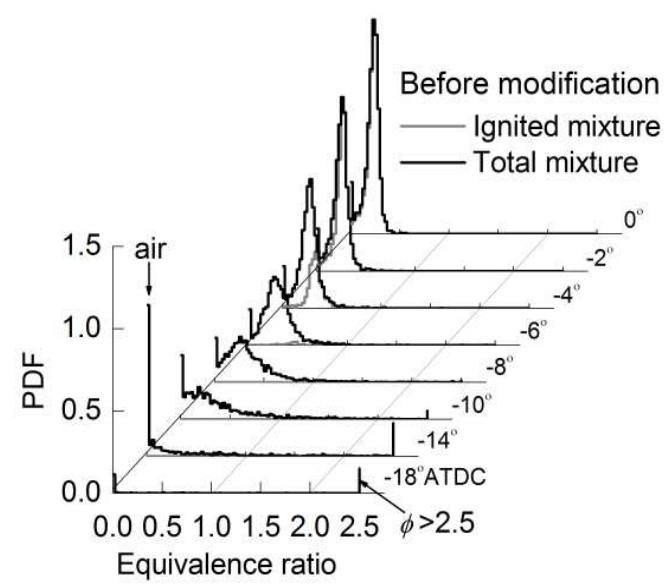

Fig. 12 PDF histories for equivalence ratio of pilot spray before modification on mixing rate $\left(q_{\text {fpilot }}=2 \mathrm{~mm}^{3}, \theta_{\text {pilot }}=-19^{\circ}\right.$ ATDC $)$

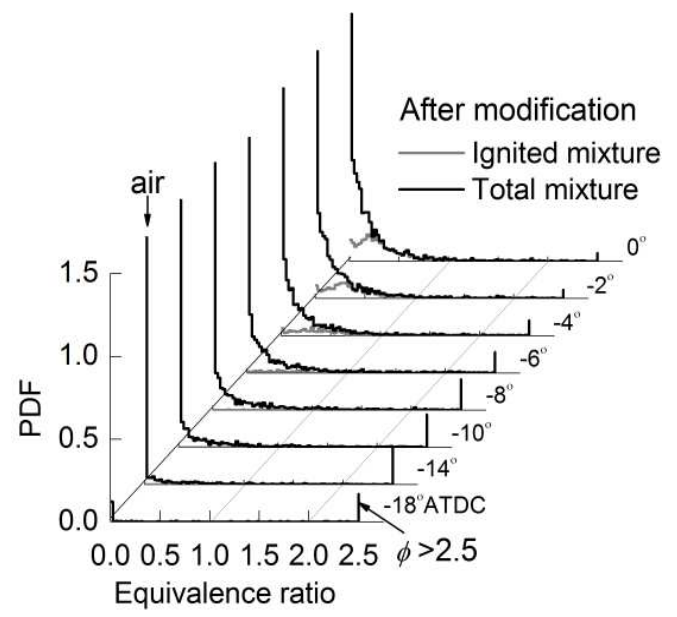

Fig. 13 PDF histories for equivalence ratio of pilot spray after modification on mixing rate $\left(q_{\text {fpilot }}=2 \mathrm{~mm}^{3}, \theta_{\text {pilot }}=-19^{\circ}\right.$ ATDC $)$

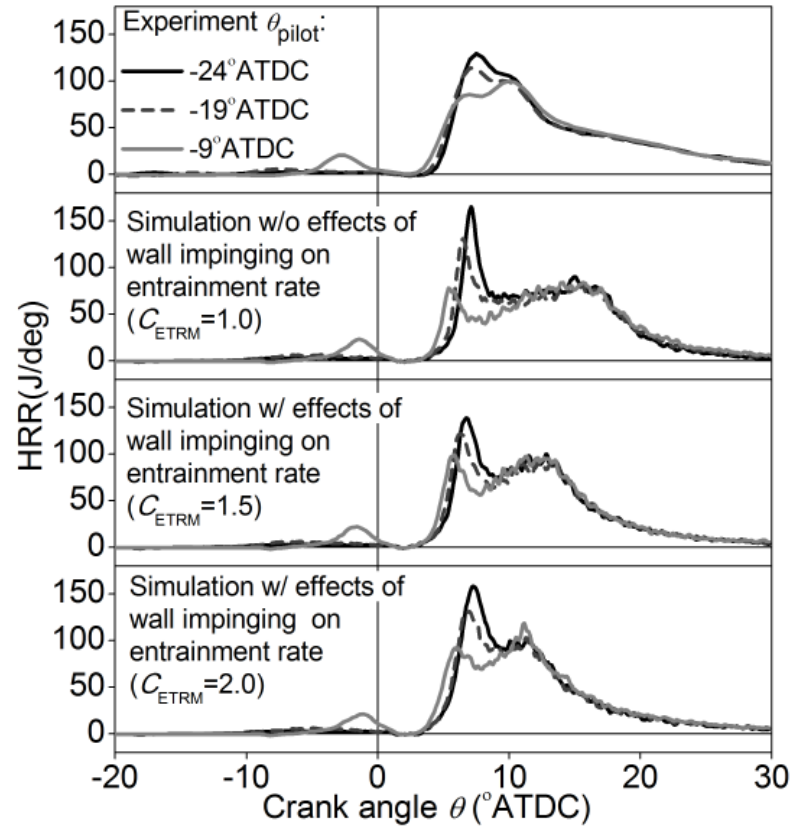

Fig. 14 Effects of pilot injection timing on heat release rate with different values of $\mathrm{C}_{\mathrm{ETRM}}$ $\left(q_{\text {fpilot }}=2 \mathrm{~mm}^{3}\right)$.

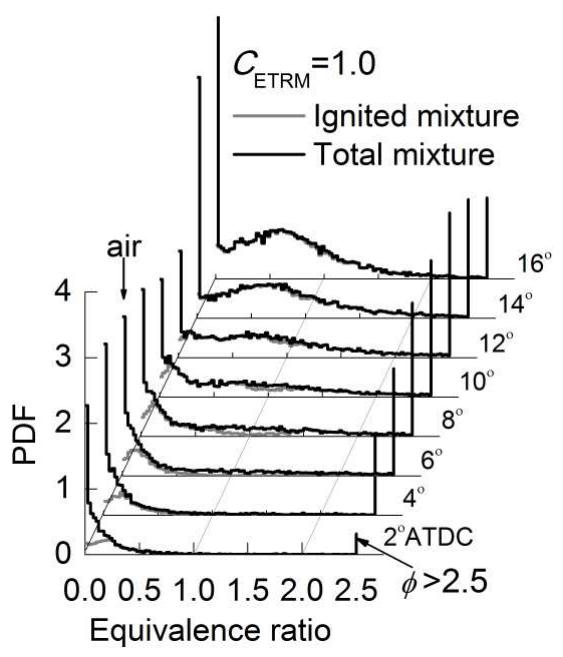

Fig. 15 PDF histories of equivalence ratio with $C_{\mathrm{ETRM}}=1.0\left(q_{\mathrm{fpilot}}=2 \mathrm{~mm}^{3}, \theta_{\text {pilot }}=-19^{\circ} \mathrm{ATDC}\right)$ 


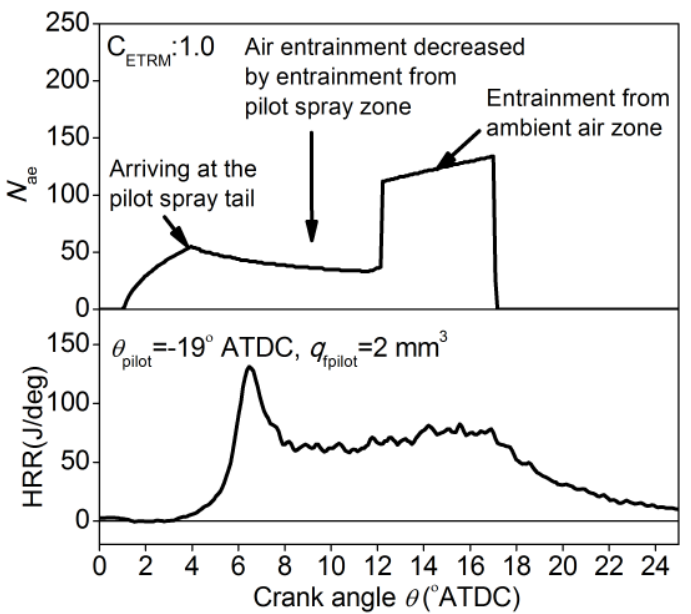

Fig. 16 Air entrainment rate and heat release rate with $C_{\text {ETRM }}=1.0\left(q_{\text {fpilot }}=2 \mathrm{~mm}^{3}, \theta_{\text {pilot }}=-19^{\circ}\right.$ ATDC $)$

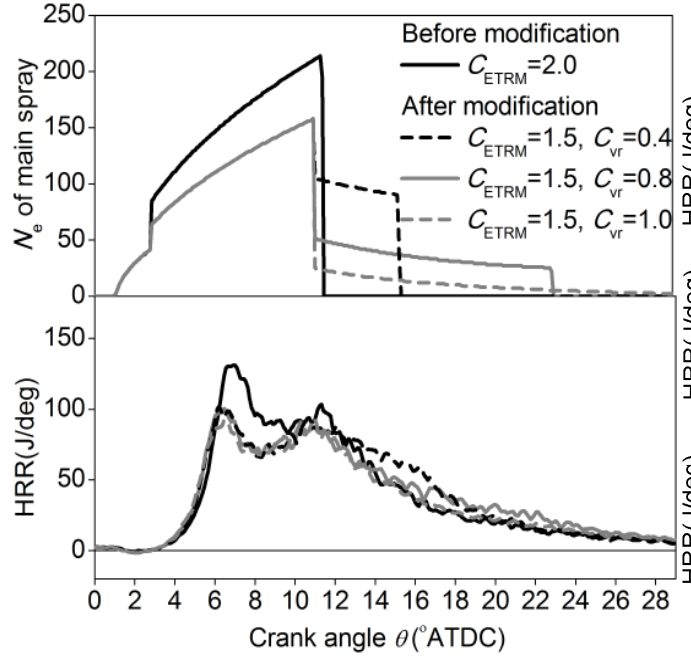

Fig. 18 Entrainment rates and heat release rates before and after modification of entrainment rate decreased by adjacent sprays interaction $\left(q_{\text {fpilot }}=2 \mathrm{~mm}^{3}, \theta_{\text {pilot }}=-19^{\circ}\right.$ ATDC $)$

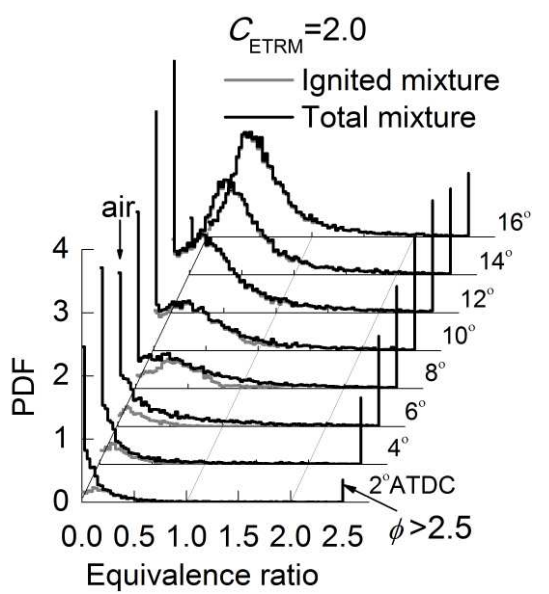

Fig. 17 Histories of PDF for equivalence ratio with $\mathrm{C}_{\text {ETRM }}=2.0\left(q_{\text {fpilot }}=2 \mathrm{~mm}^{3}, \theta_{\text {pilot }}=-19^{\circ}\right.$ ATDC $)$

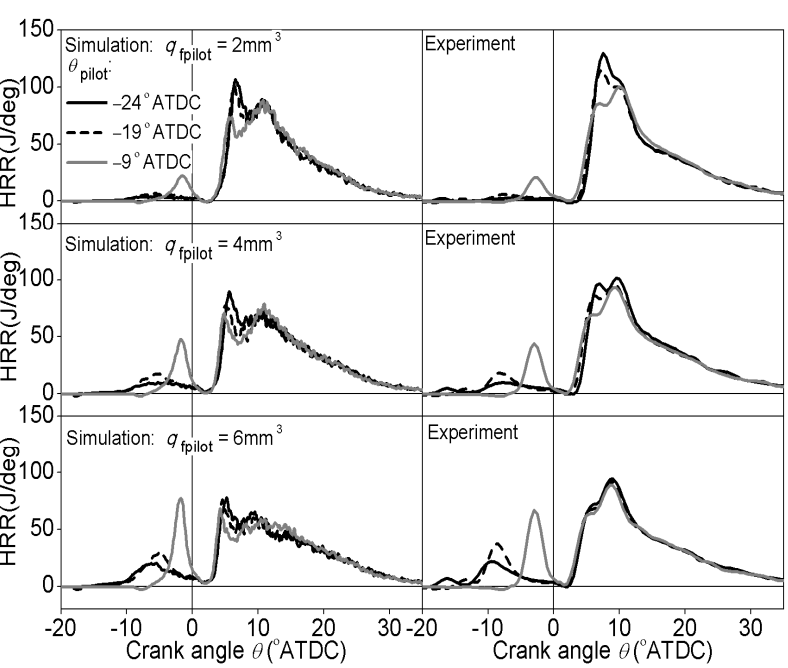

Fig. 19 Effects of pilot injection timing and injection quantity on the heat release rate

$\left(q_{\text {fpilot }}=2,4,6 \mathrm{~mm}^{3}, \theta_{\text {pilot }}=-9^{\circ},-19^{\circ},-24^{\circ}\right.$ ATDC $)$ 


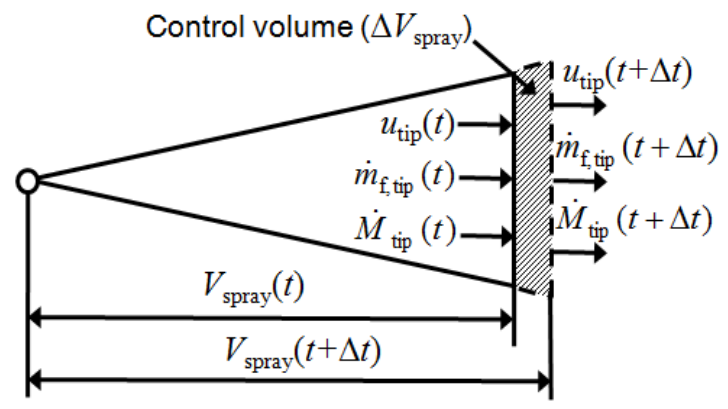

Fig. A1 Control volume selection for spray tip penetration calculation after transition timing 